\title{
Designing Annuities with Flexibility Opportunities in an Uncertain Mortality Scenario
}

\author{
Annamaria Olivieri
}

check for

updates

Citation: Olivieri, Annamaria. 2021. Designing Annuities with Flexibility Opportunities in an Uncertain Mortality Scenario. Risks 9: 189. https://doi.org/10.3390/risks9110189

Academic Editor: Mercedes Ayuso

Received: 31 August 2021

Accepted: 19 October 2021

Published: 22 October 2021

Publisher's Note: MDPI stays neutral with regard to jurisdictional claims in published maps and institutional affiliations.

Copyright: (C) 2021 by the author. Licensee MDPI, Basel, Switzerland. This article is an open access article distributed under the terms and conditions of the Creative Commons Attribution (CC BY) license (https:/ / creativecommons.org/licenses/by/ $4.0 /)$.
Department of Economics and Management, University of Parma, Via J. F. Kennedy 6, 43125 Parma, Italy; annamaria.olivieri@unipr.it.com; Tel.: +39-0521032387

\begin{abstract}
We consider annuity designs in which the benefit amount is allowed to fluctuate (up or down), based on a given mortality/longevity experience. This way, guarantees are relaxed in respect of traditional annuity arrangements. On the other hand, while the annuitant is exposed to the risk of a future reduction of the benefit amount because of higher longevity, he/she can immediately take advantage of a lower premium loading, as well as of a future increase of the benefit amount in the case of higher mortality. Flexibility in the annuity design could be welcomed by individuals, as the conservative features of traditional products partly explain their lack of attractiveness in most markets. To further contribute to the flexibility of the product, we suggest a pricing structure based on periodic fees applied to the policy fund, instead of the usual upfront loading at issue. Periodic fees are more suitable to support a revision of the arrangement after issue, which is currently not allowed in traditional annuity products. We show that periodic fees can be introduced by identifying a discount factor to be used for pricing and reserving. We assume stochastic mortality, and we compare alternative mortality/longevity linking solutions, by assessing the periodic fees and other quantities.
\end{abstract}

Keywords: mortality/longevity-linked annuities; aggregate longevity/mortality risk; longevity guarantee; periodic longevity fee

\section{JEL Classification: G22}

\section{Introduction}

The need for individuals to take autonomous decisions regarding their post-retirement income is widely recognized. Such a need has become more urgent after the adoption of Defined Contribution principles (in place of Defined Benefit) in Pillar I and II pension systems of many countries, as individuals are thus exposed to significant financial and longevity risks when in retirement. Among the private arrangements providing a postretirement income, traditional life annuities are perhaps the most protective form for individuals, thanks to the longevity and financial guarantees they provide. This suggestion is supported by the classical result by (Yaari 1965), which identifies annuities as the optimal choice for a retiree. However, guarantees of traditional annuities expose the provider to major risks, furthermore over a long-term time horizon; this is why guarantees are matched by a conservative structure of benefits and investments, with loadings judged to be very high. These are some of the reasons explaining the so-called annuity puzzle, i.e., the fact that individuals are not attracted by life annuities and markets remain underdeveloped (see, for example, (Davidoff et al. 2005) and, for a recent contribution and updated list of references, (Peijnenburg et al. 2016)).

The current pandemic may suggest that planning the post-retirement income is no longer a topical issue. On the contrary, longevity remains a matter not to be disregarded, neither by individuals nor by providers. While it is clear that the COVID-19 pandemic is currently causing a mortality shock, different scenarios about the future mortality are possible, including an increase in the life expectancy of the survivors (see, for example, 
Cairns et al. 2020; Milevsky 2020). Furthermore, social security could be in greater difficulty in the near future, due to the economic crises that have occurred in the latest years. It is, therefore, still relevant to consider situations where a significant part of the post-retirement income will have to be covered with private resources. Individuals will have to decide whether to self-annuitize their money, retaining all risks, or transfer all or part of the risks to providers, who then in turn have to develop cost-effective and attractive solutions.

In a scenario characterized by longevity but also by mortality shocks (which in the current pandemics are particularly severe at high ages), it is convenient to redefine longevity guarantees, so as to make them cheaper and more appealing both for individuals and providers. In particular, if the benefit amount is contingent on an appropriate mortality/longevity experience, possible profits and losses originated by unanticipated mortality/longevity are (at least partially) shared between individuals and providers, resulting in lower loadings, but also providing the opportunity to design a more flexible product structure.

Mortality/longevity-linked annuity benefits have been addressed in several contributions in the latest decade; see, in particular, (Bravo and de Freitas 2018; Chen and Rach 2019; Chen et al. 2019; Denuit et al. 2011; Milevsky and Salisbury 2015; Richter and Weber 2011; Weinert and Gründl 2021). Some forms already exist in the market; for example, in Danish deferred group annuities the benefit amount is increased by a bonus if the actual investment performance exceeds the guaranteed return or if the mortality experience is higher than expected (see Andersen and Skjodt 2007). While alternative linking coefficients have been examined in the literature, the problems mainly discussed are the fair valuation of the contract, as well as optimality issues for the individual, in an expected utility framework. The idea of linking a post-retirement income benefit to a mortality/longevity experience has not been developed for the first time in the latest decade, however. Conversely, such an idea is very old, dating back to the 17th century, when the so-called tontine investments were conceived. However, tontine annuities were originally designed not for protecting against the longevity risk, but for speculative purposes; see (McKever 2009) and (Milevsky 2014) for historical notes. Recently, mortality/longevity-linking structures have been adopted within pooled arrangements; while the best known are Group-Self Annuitization pools (see, for example, Piggott et al. 2005; Qiao and Sherris 2012), other schemes are investigated in (Stamos 2008), (Donnelly et al. 2013) and (Donnelly 2015), to cite some contributions. Pooled arrangements are self-insured: no guarantee is provided; individuals pool together their money, trying to take advantage of pooling effects. Self-insured solutions are cheaper than annuities, but individuals retain all risks, as members of the pool. In contrast, some forms of guarantees should be kept in mortality/longevity-linked annuities. A general description of linking coefficients, including as particular cases most of the solutions analysed in the literature both for insured and self-insured arrangements, is developed by (Olivieri and Pitacco 2020a).

As mentioned above, annuities are usually viewed as a very conservative product by individuals, as they represent an inflexible and illiquid asset, they imply an irreversible decision at issue, they do not satisfy bequest needs or they meet bequest preferences only partially, if a death benefit is included (see Pitacco 2016). Innovation can be pursued in various respects. Making the benefit amount contingent on mortality/longevity is undoubtedly an important innovation. In particular, it favours the adoption of not excessively prudential assumptions about future mortality, otherwise necessary given that annuities extend over a very long time-horizon. Bequest preferences can be met by introducing death benefits. While this is customary in annuities (as mentioned above), with death benefits payable up to some (not very high) age, Bernhardt and Donnelly (2019) introduce bequest in pooled arrangements. Several opportunities for innovation can be obtained when combining different benefits, such as the just mentioned case of annuities and death benefits. Particularly interesting in this regard is the combination of different forms of annuities; Chen et al. $(2019,2020)$ and Chen and Rach (2019) consider the case of fixed annuity benefits combined with mortality/longevity linked-benefits. 
Another line of innovation can be developed in respect of the structure of the fees. It is traditional for life annuities to define and charge the premium loading at issue, when the individual transfers their money to the provider. Such a pricing structure concurs to the inflexibility of the product, as on one hand pricing assumptions are fully chosen at issue, on the other the provider is required to pre-define the management over time of the upfront loadings. Conversely, periodic fees can pave the way for greater product flexibility, for example making it easier to switch to different forms of benefits after issue, or making it possible to revise the pricing assumptions. In this latter regard, we note that while the possibility of revising pricing assumptions can be viewed with suspicion by individuals, any change will not necessarily be to the advantage of the provider (rather, it may be favourable to the individual); in principle, any change in pricing assumptions will be limited by the policy conditions underwritten at issue. Periodic fees are a natural choice when periodic premiums are paid, i.e., usually in the case of endowments. In a mortality/longevity linking framework, Hanbali et al. (2019) focus in particular on the case of pure endowments, by assuming level premiums (subject to possible adjustments in time). Periodic fees are common in variable annuities, independent of the time-profile of the premium stream. Here, guarantees are priced by charging a periodic fee to the policy account value, with the possibility for the policyholder to waive the guarantee at any time (except for agreed time windows), with a consequent interruption of the relevant fee charge; for a general overview, see (Bacinello et al. 2011). In a recent contribution by (Chen et al. 2021) periodic fees are introduced in a tontine scheme, and are expressed as a proportion of the benefit amount; the size of the fee that makes the individual indifferent between choosing a fixed-benefit or a tontine annuity is in particular examined, identifying this way the range of acceptable fee levels in tontine arrangements.

In this paper, we consider mortality/longevity-linked annuities, that include guarantees in the form of barriers for the benefit amount. We further develop Olivieri and Pitacco (2020a, 2020b), by introducing periodic fees instead of an upfront fee at issue. Periodic fees are charged to the policy fund value and their level is assessed based on the losses and profits retained by the provider, which in turn depend on the linking coefficient and the barriers for the benefit amount. The metric we use to assess the required fees is the business value for the provider; this quantity, defined as the present value of future profits net of the cost of capital, is suitable as a joint summary of the losses and profits retained by the provider. We show that the periodic fee identifies a discount factor to be used for pricing and reserving. We then define the individual reserve, and split it into two components, one covering the value of future benefits and one the value of future fees; such an information can be useful in some applications.

The remainder of the paper is organized as follows. In Section 2, we describe the model, in particular the mortality/longevity-linking annuity benefits examined in the paper (Section 2.1), the structure of periodic fees and the corresponding discount factor (Section 2.2), the individual reserve and its components (Section 2.3), the business value to the provider (Section 2.4); finally, we discuss how to assess the required fees, based on an assessment of the business value (Section 2.5). Some numerical findings are illustrated in Section 3, more specifically in Section 3.3, after having sketched the stochastic mortality model adopted (Section 3.1) and provided details about the arrangements analysed in the numerical implementation (Section 3.2). Finally, Section 4 concludes the paper, with some final comments.

\section{Model Setup}

\subsection{Mortality/Longevity-Linked Annuity Benefits}

We consider a discrete-time annuity immediate in arrears, i.e., with payments at the end of the year. For simplicity, one cohort only is addressed, homogeneous in all respects. The entry time is 0 and the entry age is $x$. In this paper, we focus on mortality/longevity risk only, while we disregard other risks. For this reason, a deterministic financial setting is adopted. 
We follow the general linking structure described in (Olivieri and Pitacco 2020a), to which we refer for a detailed discussion about the rationale and actuarial technique backing the annuity benefit adjustment. We consider the following two alternative mortality / longevity-linked annuity benefits:

$$
\begin{aligned}
& b_{t}=b_{t-1} \cdot \frac{p_{x+t-1}(0)}{\widetilde{p}_{x+t-1}} \\
& b_{t}=b_{0} \cdot \frac{1+a_{x+t}(0)}{1+a_{x+t}(t)}
\end{aligned}
$$

where $b_{0}$ is chosen at time 0 in both cases. The meaning of the quantities in Equations (1) and (2) is as follows: $p_{x+t-1}(0)$ denotes the annual survival probability at age $x+t-$ 1 provided by a best-estimate mortality assumption (i.e., life table) at time 0 ; $\widetilde{p}_{x+t-1}$ represents the proportion of survivors (or longevity index) observed in a chosen population; $a_{x+t}(0), a_{x+t}(t)$ denote the actuarial value at age $x+t$ of a unitary discrete-time annuity in arrears, based on the best-estimate mortality assumptions (namely, life tables), respectively, at time 0 and $t$. An interpretation about the two adjustments coefficients follows below.

In Equation (1), which we will call linking by means of the survival probability, the benefit amount is adjusted based on the comparison between the survival rate realized in a given population, $\widetilde{p}_{x+t-1}$, and a benchmark, $p_{x+t-1}(0)$, chosen at time 0 . An increase (decrease) of the benefit amount follows from $p_{x+t-1}(0)>\widetilde{p}_{x+t-1}\left(p_{x+t-1}(0)<\widetilde{p}_{x+t-1}\right)$, i.e., in the case of higher realized mortality (longevity) than predicted by the benchmark. We note that, for an annuity business, a profit (loss) is typically reported by the provider in the case of higher mortality (longevity); thus, the benefit adjustment in (1) serves to mitigate such a profit (loss), partially transferring it to the individuals. The strength of the mitigation effect depends, however, on the population in which $\widetilde{p}_{x+t-1}$ is measured (as well as on other policy conditions, such as any barriers set for the benefit amount).

As far as the population is concerned, the choice is between the provider's pool or a reference population. While the provider's pool usually shows a small size and is thus subject to major random fluctuations, large reference populations are more appropriate, so that deviations between $\widetilde{p}_{x+t-1}$ and $p_{x+t-1}(0)$ can be mainly attributed to an unanticipated underlying mortality/longevity trend. Random fluctuations represent a traditional risk for insurers (and annuity providers), and the relating risk management actions should be arranged using the well-known pooling arguments. Conversely, mortality/longevitylinking benefits are recommended to cope with unanticipated mortality/longevity trends. In the following, we then assume that $\widetilde{p}_{x+t-1}$ is measured on a large population. We finally note that any possible difference between the mortality/longevity in the provider's pool and the reference population may be due not only to random fluctuations, but also to different underlying trends. A basis risk follows for the provider, which we do not address in this paper.

It is interesting to note that rule (1) is equivalent to the following:

$$
b_{t}=b_{0} \cdot \frac{t p_{x}(0)}{{ }_{t} \widetilde{p}_{x}}
$$

where ${ }_{t} p_{x}(0)$ is the survival probability from age $x$ to age $x+t$ provided by the bestestimate mortality assumption at time 0 , while ${ }_{t} \widetilde{p}_{x}$ is the proportion of survivors from age $x$ to age $x+t$ in the reference population. Equation (3) shows an important feature, which does not emerge explicitly from Equation (1): the adjustment coefficient should be applied to the benefit amount defined at the time the benchmark is referred to, namely time 0 in this case. In other words, there must be a consistency between the time-frame involved by the adjustment coefficient and the reference time of the quantity to which such a coefficient is applied.

Coming to the benefit adjustment in Equation (2), which we will call linking by means of the actuarial value of the annuity, we first note that $a_{x+t}(h)=\sum_{s=1}^{\omega-(x+t)}(1+i)^{-s}$. 
${ }_{s} p_{x+t}(h)$, where $i$ is a chosen discount rate, $s p_{x+t}(h)$ the survival probability (from age $x+t$ to age $x+t+s$ ) based on best-estimate assumptions at time $h$, and $\omega$ the maximum attainable age (that we assume to be deterministic). The ratio $\frac{1+a_{x+t}(0)}{1+a_{x+t}(t)}$ then involves a comparison between possibly different mortality assumptions (or life tables) adopted to assess the actuarial value of a unitary annuity, at time 0 and time $t$. The actuarial value in the numerator, in particular, is a benchmark. If higher (lower) mortality is forecasted at time $t$, then $a_{x+t}(0)>a_{x+t}(t)\left(a_{x+t}(0)<a_{x+t}(t)\right)$, implying an increase (reduction) of the benefit amount. Updated mortality/longevity assumptions in the actuarial value of the annuity can result in a profit (loss) for the provider, which is (partially) mitigated by the benefit adjustment. We note that, in line with what commented above for the linking by means of the survival probabilities, having set the benchmark at time 0 , the benefit adjustment is applied to the benefit amount at the same time.

Both in the linking by means of the survival probability and by means of the actuarial value of the annuity, explicit guarantees can be introduced, for example, by setting bounds for the benefit amount or the benefit adjustment. Furthermore, it is also reasonable to accept a maximum age to apply the benefit adjustment (say, age 95), in order to avoid that the individual is exposed to the risk of benefit reductions at very advanced ages.

\subsection{Policy Fund and Periodic Fees}

In this section, we describe the main setting for periodic fees. As with other annuity products, each individual only pays an initial capital $S$ at entry time 0 , and then will cash the annuity benefit annually, until death. Unlike the usual setting for annuities, where the premium loading is charged entirely to the initial capital at time 0 , we assume that periodic fees are charged to the policy fund at the beginning of each year. This is similar to what happens in variable annuities. In our discussion, we disregard expenses; the fee (whether it is obtained as a single initial or a periodic loading) is justified by the logic of the safety loading, i.e., by the fact that the arrangement incorporates guarantees whose cost is charged to the individual. When expenses are also addressed, periodic expenses can be added to the periodic fee, while an upfront loading to cover initial expenses could be included.

In this paper, we are mainly concerned with identifying appropriate pricing and reserving logics when fees are periodic. Any possible revision after issue of the fee level requires criteria that we do not address in this paper. In what follows, we assume that the periodic fee level is chosen at time 0 , and kept fixed over the whole policy duration; some comments about the possible revision of the fee level after issue will be made later, in Section 3.3.

As stated in Section 2.1, in this paper we consider a pool consisting of one cohort only, homogeneous in all respects (entry age, risk class, benefit amount). With $N_{x+t}$ we denote the number of individuals in the pool at time $t$ (age $x+t$ ). At time $0, N_{x}=n_{x}$ known, while $N_{x+t}$ is random because of the mortality in the cohort.

Let $A_{t}$ denote the individual fund (or policy fund) for a policy in-force at time $t$. No death benefit is paid out by the provider, so that upon death the policy fund is released to the pool (as a form of mortality credit). The dynamics of the policy fund is then described by the following balance equation:

$$
A_{t} \cdot N_{x+t}=A_{t-1} \cdot N_{x+t-1} \cdot(1-\xi) \cdot(1+i)-b_{t} \cdot N_{x+t},
$$

where: $\xi$ is the proportional premium loading (or fee) that is charged to each policy fund at the beginning of each year and $i$ is the (deterministic) return on investments. At time 0 , $A_{0}=S$.

The policy fund is random because of the mortality in the pool and the path of the benefit amount; in a more general setting, random financial returns can also be addressed. 
Solving backwards Equation (4) (note that $A_{\omega-x}=0$ ), we find:

$$
A_{0}=\sum_{s=1}^{\omega-x} b_{s} \cdot((1-\xi) \cdot(1+i))^{-s} \cdot \frac{N_{x+s}}{n_{x}} .
$$

Equation (5) shows that the periodic fee $\xi$ identifies a discount factor, to be used for pricing. However, in order to quantify $\xi$, we still need a valuation principle. While we know that $A_{0}=S$, the expression on the right hand side of Equation (5) is still random, as both the sequences $b_{s}$ and $N_{x+s}$ are random. Furthermore, there are two unknowns in Equation (5), namely $b_{0}$ and $\xi$. We further discuss this problem in Section 2.5, after having introduced some quantities. We point out, however, that the approach we suggest to assess the periodic fee will not directly make use of Equation (5); the discussion just developed allows us to say that the periodic fee identifies a discount factor to be used for pricing purposes (as well as for reserving; see Section 2.3).

We note that, if policy conditions admit, the periodic fee could be updated after issue first extending Equation (5) and then implementing an appropriate valuation principle. As already mentioned, in this paper we do not develop the discussion in this respect.

\subsection{Individual Reserve and Components}

In order to define the individual reserve, we make the following comments. As is well-known, the individual reserve corresponds to the best-estimate value of liabilities plus a risk margin. We assume that the risk margin can be measured through the periodic fee, which (as noted in Section 2.2) identifies a discount factor. We further assume that, to be consistent, the best-estimate assumptions should be those defined when the periodic fee was assessed, i.e., at time 0 in this paper. Consider a policy in-force at time $t$. The individual reserve is defined as follows:

$$
V_{t}=b_{t} \cdot \sum_{s=1}^{\omega-(x+t)}((1-\xi) \cdot(1+i))^{-s} \cdot{ }_{s} p_{x+t}(0) .
$$

It is useful to note that no future update of the benefit amount is explicitly considered in the definition of the individual reserve, as the periodic fee already includes in the reserve an allowance for the future benefit adjustments.

For shortness, we denote the sum in Equation (6) as $a_{x+t}(0 ; \xi)$, where the symbol $\xi$ refers to the fact that discounting is based also on the periodic fee (conversely, the notation $a_{x+t}(0)$ will be kept to denote the expression commented in Section 2.1, i.e., when discounting is based on the interest rate only).

It could be useful to split the individual reserve into components. A possible splitting is the following:

$$
V_{t}=b_{t} \cdot a_{x+t}(0 ; \xi)=b_{t} \cdot a_{x+t}(0)+b_{t} \cdot\left(a_{x+t}(0 ; \xi)-a_{x+t}(0)\right) .
$$

The first quantity, $V_{t}^{[\mathrm{ben}]}=b_{t} \cdot a_{x+t}(0)$ is the best-estimate value of future benefits, while the second, $V_{t}^{[\mathrm{fee}]}=b_{t} \cdot\left(a_{x+t}(0 ; \xi)-a_{x+t}(0)\right)$, can be interpreted as the part of the individual reserve accounting for fees. This decomposition could be useful first to identify the risk margin included in the individual reserve. It could be further useful in the case of a switch to a different benefit structure, as the provider could only use $V_{t}^{[\mathrm{ben}]}$ to determine the new benefit level or, in the case of revision of the fee, the revision itself could be limited to the component $V_{t}^{[\mathrm{fee}]}$. These aspects are not further developed in this paper.

\subsection{Pool Fund, Present Value of Future Benefits, Present Value of Future Profits and Business Value}

We now address quantities defined in the provider's perspective. Each individual in the pool pays the initial capital $S$ at time 0 , and will cash the annual amount $b_{t}$ at time $t, t=1,2, \ldots$, until death. The following quantity describes what we call the pool fund, i.e., 
the remaining money at time $t$ of the total amount of initial capital, net of the benefits paid so far and including interest on investments:

$$
F_{t}=F_{t-1} \cdot(1+i)-b_{t} \cdot N_{x+t},
$$

with $F_{0}=S \cdot n_{x}$. Periodic fees do not enter the assessment of the pool fund; indeed, as individuals transfer money to the pool only at time 0 , periodic fees do not originate a real periodic cash flow. Rather, they consist in a loading which is charged annually to the policy funds of the survivors, as expressed by Equation (4).

The difference between the pool fund and the pool reserve, namely

$$
S P_{t}=F_{t}-V_{t} \cdot N_{x+t},
$$

expresses the surplus cumulated by the provider in the time-interval $(0, t)$. If we consider the surplus cumulated over the whole pool duration $(0, \omega-x)$, we find:

$$
\begin{aligned}
S P_{\omega-x} & =S \cdot n_{x} \cdot(1+i)^{\omega-x}-\sum_{s=1}^{\omega-x} b_{s} \cdot(1+i)^{\omega-x-s} \cdot N_{x+s} \\
& =n_{x} \cdot(1+i)^{\omega-x} \cdot\left(S-\sum_{s=1}^{\omega-x} b_{s} \cdot(1+i)^{-s} \cdot \frac{N_{x+s}}{n_{x}}\right)
\end{aligned}
$$

where: $\mathrm{PVFB}_{0}=\sum_{s=1}^{\omega-x} b_{s} \cdot(1+i)^{-s} \cdot \frac{N_{x+s}}{n_{x}}$ represents the Present Value of Future Benefits (PVFB) at time 0 , expressed per policy issued. The quantity $\mathrm{PVFP}_{0}=S-\mathrm{PVFB}_{0}$ then represents the total profit, usually called Present Value of Future Profits (PVFP) at time 0, expressed per policy issued.

The PVFB and the PVFP are quantities of great interest for the assessment of the business value. Their definition can easily be extended to times after issue. If $n_{x+t}$ is the number of policies in-force (i.e., in the portfolio) at time $t$, then

$$
\mathrm{PVFB}_{t}=\sum_{s=1}^{\omega-(x+t)} b_{t+s} \cdot(1+i)^{-s} \cdot \frac{N_{x+t+s}}{n_{x+t}}
$$

expresses the PVFB at time $t$ per policy in-force at that time, while PVFP at time $t$ can be assessed as follows:

$$
\operatorname{PVFP}_{t}=V_{t}-\mathrm{PVFB}_{t}
$$

Alternative valuation assumptions can be adopted in the assessment of PVFB, PVFP, in particular with regard to mortality. The proportions $\frac{N_{x+t+s}}{n_{x+t}}$ in (12) lead to an entity-specific assessment, as the size of the total amount of future payments to be made by the provider (namely, the amounts $b_{t+s} \cdot N_{x+t+s}$ ) is measured with the number of survivors in the pool, which in their turn results from the mortality in the pool itself. Entity-specific assessments are convenient, for example, to perform a realistic valuation of provider's liabilities. The adoption of the proportion of survivors in the reference population, $s \widetilde{p}_{x+t}$, in place of $\frac{N_{x+t+s}}{n_{x+t}}$ is to be preferred in market-consistent assessments, such as those involved by pricing issues. In this case, mortality/longevity risks to which the provider is exposed (e.g., because of a small pool size or a pool composition affected by adverse-selection), but could be offset by appropriate market transactions, should be excluded from the valuation. Since we are discussing the setting of appropriate fees, in this paper we follow a market-consistent logic, and we disregard risks specific to the provider. In particular, we do not consider different mortality situations between the provider's pool and the reference population, so that we accept $\frac{N_{x+t+s}}{n_{x+t}}={ }_{s} \widetilde{p}_{x+t}$ at any age.

For further details about the assessment of PVFB and PVFP in more general situations, we refer to Olivieri and Pitacco (2020a, 2020b). 
We now assess the business value for the provider, which is the part of PVFP net of the cost of capital that the provider is required to hold to manage the business (for references and an application to traditional annuities, see Blackburn et al. 2017). We assess the cost of capital in a market-consistent style, i.e., as frictional costs net of the value of the limited liability put option. The limited liability put option takes a positive value when, because of the possible depletion of capital, the provider may fail to meet (at least in part) its obligations. We assume that the provider can always obtain the extra capital necessary to fulfil all obligations, in the case the amount initially allocated to the pool becomes insufficient. In this case, the limited liability put option takes a null value. Frictional costs (which arise mainly because of agency costs) are usually assessed as a proportion $\rho$ of the capital held on top of the pool reserve. We assume that such a capital is in the amount required by regulation; we denote with $\mathrm{RC}_{t}$ the capital required at time $t$ per policy in-force at that time. The annual frictional cost per policy in-force at the beginning of the year is then:

$$
\mathrm{FC}_{t}=\rho \cdot \mathrm{RC}_{t-1}
$$

The present value of frictional costs at time $t$, per policy in-force, is obtained as follows:

$$
\mathrm{PVFC}_{t}=\sum_{s=1}^{\omega-(x+t)} \mathrm{FC}_{t+s} \cdot(1+i)^{-s} \cdot{ }_{s} \widetilde{p}_{x+t} .
$$

We assess $\mathrm{RC}_{t}$ following the Solvency 2 principles, which require an amount of capital so to avoid default with $99.5 \%$ probability, allowing only for risks non-diversifiable on the market. A long-term time horizon in which to assess possible defaults seems the most logical choice in respect of longevity risk, due to its long-term nature. We obtain the required capital at time $t$ per policy in-force from the following condition:

$$
\operatorname{Pr}\left(\mathrm{RC}_{t}+V_{t}<\mathrm{PVFB}_{t}\right)=0.005 .
$$

Finally, we define the business value at time $t$, per policy in-force, as follows:

$$
\mathrm{BV}_{t}=\mathrm{PVFP}_{t}-\mathrm{PVFC}_{t}
$$

\subsection{Setting the Periodic Fee}

As is well-known (see, for example, Duffie 2001), the market price of a security is given by the present value of its expected cash flows, where the present value is assessed with the risk-free rate and the expected value is obtained with a suitably risk-adjusted probability measure. When the market is incomplete, as is the case for example of insurance and pension markets, there are infinite suitable probability measures, among which the provider has to choose one to price the annuity contract. This approach apparently contrasts with the traditional insurance pricing model, which first employs best-estimate assumptions, and then adds an implicit or explicit safety loading. The safety loading, in particular, represents the expected profit to the provider and its size should be justified by the risks taken by the provider itself. What is common to both approaches is that the expected profit to the provider is 0 under the chosen valuation assumptions; however, a reward for the retained risks is included, either through the risk-adjustment of the probabilities or the safety loading.

Mortality/longevity-linked annuities certainly require an innovative pricing approach, as they imply a new concept of longevity guarantee, as we have commented in Sections 1 and 2.1. It could be convenient to match somehow market principles with the traditional model. To this aim, we note that of the various quantities described so far, there is one explicitly affected both by expected profits and the risks borne by the provider, which is the business value. Risks, in particular, affect the business value via frictional costs, as they are proportional to the required capital, whose size in turn depends on the potential losses 
reported by the provider, apart from the largest losses as identified by the accepted default probability.

We extend the 0 expected profit principle to the business value. Adopting the periodic fee structure described in Section 2.2, at time 0 we assess the periodic fee $\xi$ so that

$$
\mathbb{E}\left[\mathrm{BV}_{0}\right]=0 .
$$

Such an equation can be solved once a (stochastic) mortality model describing the mortality/longevity of the reference population has been chosen. In Section 3.1, we briefly describe the model that we have adopted in the numerical implementation.

We now address some computational issues. First we note that Equation (18) reasonably requires stochastic simulation, although this depends on the mortality model (however, one can hardly count on closed formulae). Second, as already noted (see Section 2.2), given $S$, there are two unknowns in the relevant equations, namely $b_{0}$ and $\xi$, which among other things are related, as the higher is $\xi$, the lower is $b_{0}$, and vice versa. Whatever is the approach adopted (market-based, traditional or the one we are discussing), there is one degree of freedom, in respect of which we proceed as follows. First we set $\xi=0$ and assess $b_{0}$ solving Equation (6), for $t=0$ (having $V_{0}=S$, at that time). We denote such an initial benefit amount as $b_{0}^{*}$; in practice, $b_{0}^{*}=\frac{S}{a_{x}(0)}$. Then we assess the expected business value, under $b_{0}^{*}$; we use the notation $\mathrm{BV}_{0}^{*}=\mathbb{E}\left[\mathrm{BV}_{0} ; b_{0}^{*}\right]$; if such a quantity is $\neq 0$ (reasonably, it takes a negative value), we adjust (typically, we reduce) the initial benefit amount, so to reach a value 0 for the business value. In practice, we set $V_{0}^{[\text {fee] }}=-\mathrm{BV}_{0}^{*}$ and we find $b_{0}=\frac{S-V_{0}^{[f e e]}}{a_{x}(0)}$ (see Equation (7)). Finally, we find the periodic fee $\xi$ by solving at time $t=0$ Equation (6) (which has now only one unknown) in respect of $\xi$ (here, we can use a routine for the internal rate of return). We point out that once $b_{0}$ and $\xi$ have been set, we cannot exclude that $\mathbb{E}\left[\mathrm{BV}_{0}\right] \neq 0$. This is because the components of $\mathrm{BV}_{0}$ are not necessarily proportional to $b_{0}$ and usually they are not proportional to $\xi$. Equation (18) is used to set the fee in a consistent way in the various situations (in particular, working with different mortality/longevity-linking coefficients), but (as we will see in the numerical implementation in Section 3) the fee thus determined can still entail value creation for the provider.

\section{Results}

\subsection{Mortality Model}

A stochastic mortality model is required to simulate the survival rates realized in the reference population and in the pool, as well as to obtain updated best-estimate assumptions at every time, consistently with the simulated experience. After the seminal paper by (Lee and Carter 1992), a very prolific research has developed on the stochastic modelling of mortality. Several models are described in the literature; most of them are suitable to obtain accurate projections at the initial time, but can present computational complexity when processing future best-estimate assumptions. Here we adopt a model discussed in (Olivieri and Pitacco 2009), which fits the evaluation needs mentioned above, and is computationally tractable. Below, we recall the main features of the model, referring to (Olivieri and Pitacco 2009) for details.

We refer to a given cohort and denote with $\widetilde{q}_{x+t}=1-\widetilde{p}_{x+t}$ the random mortality rate at age $x+t$. We define $\widetilde{q}_{x+t}$ as follows:

$$
\tilde{q}_{x+t}=q_{x+t}(0) \cdot Z_{x+t}
$$

where: $q_{x+t}(0)=1-p_{x+t}(0)$ is the mortality rate based on best-estimate assumptions at time $0 ; Z_{x+t}$ is a (positive) random coefficient (ensuring $0 \leq \widetilde{q}_{x+t} \leq 1$ ) which measures the deviation of the observed mortality rate compared to the best-estimate one at time 0 . We assume: 


$$
Z_{x+t} \sim \operatorname{Gamma}\left(\alpha_{x+t}, \beta_{x+t}\right) ;
$$

a Gamma distribution also follows for $\widetilde{q}_{x+t}$, with parameters obtained from those in (20). If the Poisson distribution is accepted for the annual number of deaths reported by the cohort, conditional on a given value for the mortality rate, then the unconditional distribution of the annual number of deaths is described by a negative binomial (or Poisson-Gamma) law. We point out that while the Poisson distribution describes random fluctuations in mortality, the Gamma (i.e., the coefficient $Z_{x+t}$, whatever is its probability distribution) describes aggregate deviations.

The parameters of (20) are first chosen at time 0 , when the cohort starts being observed; thus, $\alpha_{x+t}=\bar{\alpha}_{0}$ and $\beta_{x+t}=\bar{\beta}_{0}$ at time 0 , where $\bar{\alpha}_{0}, \bar{\beta}_{0}$ are given values. Then, year after year the parameters are updated, through an inferential procedure based on the information carried by the observed annual number of deaths. In particular, after $h$ years of observation, once the numbers of deaths $d_{x}, d_{x+1}, \ldots, d_{x+h-1}$ and the number of survivors $n_{x}, n_{x+1}=n_{x}-d_{x}, \ldots, n_{x+h-1}=n_{x+h-2}-d_{x+h-2}$ have been reported, the initial $\bar{\alpha}_{0}, \bar{\beta}_{0}$ are replaced with the following values: $\bar{\alpha}_{h}=\bar{\alpha}_{0}+d_{x}+d_{x+1}+\cdots+d_{x+h-1}, \bar{\beta}_{h}=\bar{\beta}_{0}+$ $n_{x} \cdot q_{x}(0)+n_{x+1} \cdot q_{x+1}(0)+\cdots+n_{x+h-1} \cdot q_{x+h-1}(0)$. Updating the parameters $\alpha_{x+t}, \beta_{x+t}$ introduces an implicit correlation among the coefficients $Z_{x+t}$ 's, which is something one expects when an underlying longevity trend drives mortality. Nevertheless, fluctuations in the number of deaths in the opposite direction in respect of the prevailing trend are still admitted at any time. We point out that updating the parameters of the probability distribution of $Z_{x+t}$ allows to update the current best-estimate assumptions, as well as the projection of the future number of survivors in the cohort. Details of the inferential procedure are described in (Olivieri and Pitacco 2009).

In the numerical implementation, we consider a cohort initial age $x=65$. We set $\bar{\alpha}_{0}=\bar{\beta}_{0}$, so to have $\mathbb{E}_{0}\left[Z_{x+t}\right]=1, \mathbb{E}_{0}\left[\widetilde{q}_{x+t}\right]=q_{x+t}(0)$ (we specify in the subscript of the symbol $\mathbb{E}$ the time at which the expected value is assessed, thus meaning that the state of information about mortality is specified at that time). Based on the information gained from the observed number of deaths up to time $h$, the best-estimate mortality rate is reassessed as $q_{x+t}(h)=\frac{\bar{\alpha}_{h}}{\bar{\beta}_{h}} \cdot q_{x+t}(0)$, where $\frac{\bar{\alpha}_{h}}{\bar{\beta}_{h}} \lesseqgtr 1$, depending the realized mortality path. The best-estimate mortality rates $q_{x+t}(0)$ are modelled through a Gompertz law with parameters as in (Bacinello et al. 2018). The remaining expected lifetime at age 65 is almost 20 years at time 0 ; to avoid distortions from major random fluctuations at the highest ages, the cohort is examined up to age 100 (any payments beyond that age is disregarded). The values $\bar{\alpha}_{0}=\bar{\beta}_{0}=100 \bar{\alpha}_{0}=\bar{\beta}_{0}=1000$ are alternatively adopted; if $\bar{\alpha}_{0}=\bar{\beta}_{0}=100$, the coefficient of variation of $Z_{x+t}$ at time 0 is 0.1 , while it is 0.0316 if $\bar{\alpha}_{0}=\bar{\beta}_{0}=1000$. Given the meaning of $Z_{x+t}$, the former choice of $\bar{\alpha}_{0}, \bar{\beta}_{0}$ then depicts a situation with a higher dispersion in aggregate mortality than the latter choice. To distinguish the two alternative scenarios, shortly we will refer to the choice $\bar{\alpha}_{0}=\bar{\beta}_{0}=100$ as to a scenario with major aggregate deviations; the term moderate aggregate deviations will be used instead to refer to the choice $\bar{\alpha}_{0}=\bar{\beta}_{0}=1000$ (it is useful to stress that the adjectives 'moderate' and 'major' do not have an absolute meaning here, but they are used in comparative terms between the two situations).

\subsection{Benefit Arrangements}

We examine the following arrangements:

1. Fixed benefit : $b_{t}=b_{0}$ for all times $t$.

2. Linking by means of the survival probability, with benefit amount defined by Equation (3).

3. Linking by means of the actuarial value of a unitary annuity, with benefit amount defined by Equation (2).

Arrangement 1 represents a standard case, to which arrangements with a mortality/longevity linking can be compared. For arrangements 2 and 3, barriers to the benefit 
amount are adopted, both on an annual and a global basis. Year by year, we require $0.9 \cdot b_{t-1} \leq b_{t} \leq 1.1 \cdot b_{t-1}$, so to avoid strong variations in the benefit amount from one year to the next. In respect of the possible total variation of the benefit amount we consider two cases, implying a different proportion of the risk sharing between the provider and the individual. Specifically, we require alternatively:

- $\quad$ Case (a): $0.75 \cdot b_{0} \leq b_{t} \leq 1.25 \cdot b_{0}$;

- $\quad$ Case (b): $0.9 \cdot b_{0} \leq b_{t} \leq 1.1 \cdot b_{0}$.

Finally, we admit that the benefit amount can be updated up to age 95; beyond that age, the benefit amount keeps flat, at the latest updated level.

As mentioned earlier, we disregard financial risk and we adopt a deterministic setting in this regard. Our aim is to make a comparison of the periodic fees and other quantities for the alternative linking solutions. These comparisons are not affected by the interest rate level, when it is deterministic. Thus, we simplify and take $i=0$, supported in this choice by the low level of interest rates in recent years.

\subsection{Implementation and Discussion}

In the implementation discussed in this section, the main purpose is to compare the periodic fees required for alternative annuity designs. Some of the quantities described in Section 2 are additionally quoted, in particular the components of the individual reserve, the present value of future profits and the business value. Rather than the absolute values we have obtained for the various quantities, it is the comparison between them that is significant. While absolute values are affected by the various choices made, in particular with regard to the mortality model and the interest rate, their comparison allows a better understanding of what the various linking mechanisms imply, in respect of alternative choices. All assessments have been developed simulating the number of survivors in the reference population; the same proportion of survivors than those of the reference population has been adopted for the pool. The information gained from the mortality observed in the reference population has also been used to update the best-estimate mortality assumptions after issue. The initial capital paid by each individual is $S=100$ monetary units.

Table 1 quotes the periodic fee, assessed as described in Section 2.5, for alternative arrangements. The proportion $\rho$ of frictional costs has been set to $2 \%$, following market practice (see Blackburn et al. 2017). Tables 2 and 3 list the expected value, the 0.01- and the 0.99 -quantiles of the benefit amounts for some times $t$ and for the various arrangements. It is convenient to analyse these three tables jointly, as the time-profile of the benefit amounts helps understanding the size of the fee, while the latter explains the differences among the initial benefit amounts $b_{0}$ under the different arrangements.

The arrangement with fixed benefits can be used as a reference case. It requires the highest fees, due to the absence of any form of risk sharing between the provider and the individual. In comparison, mortality/longevity-linking arrangements require lower fees, as they imply, in particular, possible reductions of the benefit amount. When interpreting the results, it should be remembered that when the benefit is linked to a mortality/longevity experience, either by means of the survival probability or the actuarial value of the annuity, the benefit is allowed both to decrease (and this implies a sharing of losses due to higher longevity) and increase (in this case, profits due to higher mortality are shared). The size of the fee is affected by the extent of the possible reduction in losses to the provider, but also by that of profits.

Overall, it seems that the fee is much affected by the loss sharing effect. This emerges, for example, when comparing the cases (a) and (b) for the linking by means of the survival probability; indeed, narrower barriers for the benefit amount imply in particular a reduced participation to possible losses. 
The importance of the magnitude of possible losses as a key to interpreting the level of the required fee also emerges when comparing (for any given arrangement) a scenario with moderate deviations in aggregate mortality to one with major deviations. Higher fees are required under the latter scenario. In this regard, it is useful to note that deviations are admitted in terms both of higher and lower mortality rates. Under a scenario with major deviations, higher fees are required; this suggests that the fee itself is in particular affected by the possibility to share the possible losses occurring because of lower mortality rates.

When comparing the fees required for arrangement where benefits are linked by means of the survival probability in the different cases, a univocal behaviour emerges. The same does not happen for arrangements where benefits are linked by means of the actuarial value of the annuity; in this latter case, it seems that the trade-off between profits and losses assumes a different balance depending on the parameters accepted for the benefit barriers and the mortality scenario. For example, $\xi$ takes the same value in a scenario of moderate aggregate deviations, independent of the barriers we have tested for the benefit amount (clearly, a different choice for such barriers could result in a different value for the required fee). From Table 2 we see also that the expected benefit amount and the 0.01- and 0.99-quantiles coincide (apart from roundings) in the two cases (a) and (b).

In principle, the coefficient linking the benefits to the survival rate implies a different time-profile of the adjustments when compared to the coefficient linking the benefit to the actuarial value of the annuity. This is shown, for example, by the quantiles of the benefit amounts quoted in Tables 2 and 3. For a given mortality scenario, the coefficient linking the benefits to the actuarial value of the annuity implies a larger benefit adjustment in earlier times than the coefficient linking the benefit to the survival probability; on the other hand, lower adjustments are then required later in time by the former coefficient. This effect can be explained by the time-horizon referred to by the quantities in the adjustment coefficient; if we compare (3) with (2), we can realize that the actuarial value of the annuity refers to a longer time-horizon than the survival probability in the early years of the annuity (i.e., when $t$ is small); the opposite happens when $t$ is high. The time-profile of the adjustments has an impact on the size of the cash flows, and then on the proportion of the total profits and losses retained by the provider, as well as on the fee.

Table 1. Periodic fee $\xi$ (to be charged each year to the policy fund value).

\begin{tabular}{lcc}
\hline Arrangement & $\begin{array}{c}\text { Moderate Aggregate } \\
\text { Deviations }\end{array}$ & $\begin{array}{c}\text { Major Aggregate } \\
\text { Deviations }\end{array}$ \\
\hline $\begin{array}{l}\text { Fixed benefits } \\
\text { Benefits linked to surv. prob., }\end{array}$ & $0.069 \%$ & $0.242 \%$ \\
case (a) & $0.003 \%$ & $0.025 \%$ \\
$\begin{array}{l}\text { Benefits linked to act. value, } \\
\text { case (a) }\end{array}$ & $0.013 \%$ & $0.033 \%$ \\
$\begin{array}{l}\text { Benefits linked to surv. prob., } \\
\text { case (b) }\end{array}$ & $0.006 \%$ & $0.093 \%$ \\
$\begin{array}{l}\text { Benefits linked to act. value, } \\
\text { case (b) }\end{array}$ & $0.013 \%$ & $0.019 \%$ \\
\hline
\end{tabular}


Table 2. Benefit amount $b_{t}$ (expected value and 0.01- and 0.99-quantiles) for selected times. Moderate aggregate deviations.

\begin{tabular}{|c|c|c|c|c|c|c|c|}
\hline \multirow[t]{2}{*}{ Time $t$} & \multirow[t]{2}{*}{$\begin{array}{c}\text { Fixed } \\
\text { benefits }\end{array}$} & \multicolumn{4}{|c|}{$\begin{array}{c}\text { Benefits Linked to Surv. } \\
\text { Prob., Case (a) }\end{array}$} & \multicolumn{2}{|c|}{$\begin{array}{c}\text { Benefits Linked to Act. } \\
\text { Value, Case (a) }\end{array}$} \\
\hline & & $\begin{array}{l}\text { Exp. } \\
\text { value }\end{array}$ & $\begin{array}{l}0.01- \\
\text { quant. }\end{array}$ & $\begin{array}{l}\text { 0.99- } \\
\text { quant. }\end{array}$ & $\begin{array}{l}\text { Exp. } \\
\text { value }\end{array}$ & $\begin{array}{l}0.01- \\
\text { quant. }\end{array}$ & $\begin{array}{l}0.99- \\
\text { quant. }\end{array}$ \\
\hline 0 & 5.199 & 5.242 & & & 5.236 & & \\
\hline 5 & 5.199 & 5.242 & 5.213 & 5.272 & 5.236 & 5.069 & 5.408 \\
\hline 10 & 5.199 & 5.242 & 5.168 & 5.320 & 5.236 & 5.052 & 5.426 \\
\hline 15 & 5.199 & 5.242 & 5.097 & 5.398 & 5.236 & 5.037 & 5.443 \\
\hline 20 & 5.199 & 5.243 & 4.984 & 5.526 & 5.236 & 5.029 & 5.454 \\
\hline 25 & 5.199 & 5.246 & 4.805 & 5.741 & 5.236 & 5.037 & 5.447 \\
\hline 30 & 5.199 & 5.253 & 4.527 & 6.114 & 5.236 & 5.093 & 5.388 \\
\hline \multirow[t]{2}{*}{ Time $t$} & & \multicolumn{4}{|c|}{$\begin{array}{c}\text { Benefits Linked to Surv. } \\
\text { Prob., Case (b) }\end{array}$} & \multicolumn{2}{|c|}{$\begin{array}{c}\text { Benefits Linked to Act. } \\
\text { Value, Case (b) }\end{array}$} \\
\hline & & $\begin{array}{l}\text { Exp. } \\
\text { value }\end{array}$ & $\begin{array}{l}0.01- \\
\text { quant. }\end{array}$ & $\begin{array}{l}\text { 0.99- } \\
\text { quant. }\end{array}$ & $\begin{array}{l}\text { Exp. } \\
\text { value }\end{array}$ & $\begin{array}{l}0.01- \\
\text { quant. }\end{array}$ & $\begin{array}{l}0.99- \\
\text { quant. }\end{array}$ \\
\hline 0 & & 5.240 & & & 5.236 & & \\
\hline 5 & & 5.240 & 5.211 & 5.270 & 5.236 & 5.069 & 5.408 \\
\hline 10 & & 5.240 & 5.166 & 5.318 & 5.236 & 5.052 & 5.426 \\
\hline 15 & & 5.240 & 5.095 & 5.396 & 5.236 & 5.037 & 5.443 \\
\hline 20 & & 5.241 & 4.982 & 5.524 & 5.236 & 5.029 & 5.454 \\
\hline 25 & & 5.243 & 4.804 & 5.739 & 5.236 & 5.037 & 5.447 \\
\hline 30 & & 5.244 & 4.716 & 5.764 & 5.236 & 5.093 & 5.388 \\
\hline
\end{tabular}

Table 3. Benefit amount $b_{t}$ (expected value and 0.01- and 0.99-quantiles) for selected times. Major aggregate deviations.

\begin{tabular}{|c|c|c|c|c|c|c|c|}
\hline \multirow[t]{2}{*}{ Time $t$} & \multirow[t]{2}{*}{$\begin{array}{c}\text { Fixed } \\
\text { benefits }\end{array}$} & \multicolumn{4}{|c|}{$\begin{array}{c}\text { Benefits Linked to Surv. } \\
\text { Prob., Case (a) }\end{array}$} & \multicolumn{2}{|c|}{$\begin{array}{l}\text { Benefits Linked to Act. } \\
\text { Value, Case (a) }\end{array}$} \\
\hline & & $\begin{array}{l}\text { Exp. } \\
\text { value }\end{array}$ & $\begin{array}{l}0.01- \\
\text { quant. }\end{array}$ & $\begin{array}{l}0.99- \\
\text { quant. }\end{array}$ & $\begin{array}{l}\text { Exp. } \\
\text { value }\end{array}$ & $\begin{array}{l}0.01- \\
\text { quant. }\end{array}$ & $\begin{array}{l}0.99- \\
\text { quant. }\end{array}$ \\
\hline 0 & 5.090 & 5.228 & & & 5.223 & & \\
\hline 5 & 5.090 & 5.228 & 5.143 & 5.326 & 5.221 & 4.717 & 5.784 \\
\hline 10 & 5.090 & 5.228 & 5.011 & 5.487 & 5.222 & 4.671 & 5.846 \\
\hline 15 & 5.090 & 5.231 & 4.806 & 5.757 & 5.223 & 4.629 & 5.905 \\
\hline 20 & 5.090 & 5.240 & 4.494 & 6.223 & 5.224 & 4.607 & 5.946 \\
\hline 25 & 5.090 & 5.253 & 4.030 & 6.534 & 5.225 & 4.635 & 5.929 \\
\hline 30 & 5.090 & 5.247 & 3.921 & 6.534 & 5.226 & 4.804 & 5.736 \\
\hline \multirow[t]{2}{*}{ Time $t$} & & \multicolumn{4}{|c|}{$\begin{array}{c}\text { Benefits Linked to Surv. } \\
\text { Prob., Case (b) }\end{array}$} & \multicolumn{2}{|c|}{$\begin{array}{c}\text { Benefits Linked to Act. } \\
\text { Value, Case (b) }\end{array}$} \\
\hline & & $\begin{array}{l}\text { Exp. } \\
\text { value }\end{array}$ & $\begin{array}{r}0.01- \\
\text { quant. }\end{array}$ & $\begin{array}{l}\text { 0.99- } \\
\text { quant. }\end{array}$ & $\begin{array}{l}\text { Exp. } \\
\text { value }\end{array}$ & $\begin{array}{r}0.01- \\
\text { quant. }\end{array}$ & $\begin{array}{l}\text { 0.99- } \\
\text { quant. }\end{array}$ \\
\hline 0 & & 5.184 & & & 5.231 & & \\
\hline 5 & & 5.185 & 5.101 & 5.282 & 5.229 & 4.725 & 5.755 \\
\hline 10 & & 5.185 & 4.970 & 5.442 & 5.229 & 4.708 & 5.755 \\
\hline 15 & & 5.187 & 4.767 & 5.703 & 5.229 & 4.708 & 5.755 \\
\hline 20 & & 5.185 & 4.666 & 5.703 & 5.229 & 4.708 & 5.755 \\
\hline 25 & & 5.179 & 4.666 & 5.703 & 5.231 & 4.708 & 5.755 \\
\hline 30 & & 5.175 & 4.666 & 5.703 & 5.233 & 4.812 & 5.745 \\
\hline
\end{tabular}

Table 4 quotes the initial fee $\pi$ equivalent to the periodic fees in Table 1 , obtained from the following condition: 


$$
S=b_{0} \cdot a_{x}(0) \cdot(1+\pi) .
$$

We note that Equation (21) represents the standard approach to premium loading for annuities. As for the periodic fee, a valuation principle is required, or an explicit choice of $\pi$, given that Equation (21) has two unknowns (namely, $b_{0}$ and $\pi$ ). Here, we assess $\pi$ consistently with what performed for $\xi$, i.e., solving Equation (18).

The fees quoted in Table 4 can be compared as discussed for Table 1. When comparing Table 4 with Table 1, we obtain an assessment of the overall loading implied by a given periodic fee. Among the advantages of periodic fees when compared to an upfront loading, we mention the fact that their structure is similar to that of other products, in particular financial investments; then, periodic fees can represent a solution in which individuals are more confident, being more familiar with such a pricing structure. Furthermore, as already mentioned, the application of periodic fees makes it easier to change the guarantee at some point in time, since in the event of a switch from a benefit structure to another the provider can stop applying the current fee and determine the new level according to the new underwritten guarantee, similarly to what happens (for example) in variable annuities. We also note that periodic fees may allow a revision of the pricing basis after issue, if justified by the emerging scenario and if admitted by policy conditions. In this respect, it is necessary to predefine appropriate triggers identifying situations where a revision of the fee is justified. Triggers could, for example, be related to a mortality/longevity index, or a measure of value to the provider, or the default probability of the provider. This topic deserves a specific research, and is not further developed in this paper.

Table 4. Equivalent initial fee $\pi$ (to be charged to the initial capital).

\begin{tabular}{lcc}
\hline Arrangement & $\begin{array}{c}\text { Moderate Aggregate } \\
\text { Deviations }\end{array}$ & $\begin{array}{c}\text { Major Aggregate } \\
\text { Deviations }\end{array}$ \\
\hline $\begin{array}{l}\text { Fixed benefits } \\
\text { Benefits linked to surv. prob., }\end{array}$ & $0.845 \%$ & $2.933 \%$ \\
$\begin{array}{l}\text { case (a) } \\
\text { Benefits linked to act. value, } \\
\text { case (a) }\end{array}$ & $0.038 \%$ & $0.311 \%$ \\
$\begin{array}{l}\text { Benefits linked to surv. prob., } \\
\text { case (b) }\end{array}$ & $0.155 \%$ & $0.400 \%$ \\
$\begin{array}{l}\text { Benefits linked to act. value, } \\
\text { case (b) }\end{array}$ & $0.155 \%$ & $1.132 \%$ \\
\hline
\end{tabular}

Table 5 lists the individual reserve $V_{t}$ and its components, namely $V_{t}^{[\mathrm{ben}]}$ and $V_{t}^{[\mathrm{fee}]}$, for a sample of times and a sample of linking arrangements. First we note that at time 0 the proportion $\frac{V_{t}^{\text {[fee] }}}{V_{t}}$ corresponds to the equivalent initial fee $\pi$; then, such a proportion decreases in time, as it is quite natural, given that the time-horizon of the obligation of the provider gradually reduces. In the table we only include some arrangements and only a scenario of moderate aggregate deviations, as other situations suggest similar comments. 
Table 5. Individual reserve $V_{t}$ and components $V_{t}^{[\mathrm{ben}]}, V_{t}^{[\mathrm{fee}]}$, at selected times $t$. Moderate aggregate deviations.

\begin{tabular}{|c|c|c|c|c|}
\hline \multicolumn{5}{|c|}{ Fixed Benefits } \\
\hline Time $t$ & Age $x+t$ & $V_{t}$ & $\frac{V_{t}^{[\text {ben }]}}{V_{t}}$ & $\frac{V_{t}^{[\text {fee }]}}{V_{t}}$ \\
\hline 0 & 65 & 100.000 & $99.155 \%$ & $0.845 \%$ \\
\hline 5 & 70 & 80.512 & $99.286 \%$ & $0.714 \%$ \\
\hline 10 & 75 & 62.970 & $99.410 \%$ & $0.590 \%$ \\
\hline 15 & 80 & 47.576 & $99.525 \%$ & $0.475 \%$ \\
\hline 20 & 85 & 34.378 & $99.632 \%$ & $0.368 \%$ \\
\hline 25 & 90 & 23.095 & $99.736 \%$ & $0.264 \%$ \\
\hline 30 & 95 & 12.387 & $99.847 \%$ & $0.153 \%$ \\
\hline \multicolumn{5}{|c|}{ Benefits Linked to Surv. Prob., Case (a) } \\
\hline Time $t$ & Age $x+t$ & $V_{t}$ & $\frac{V_{t}^{[\text {ben }]}}{V_{t}}$ & $\frac{V_{t}^{[\mathrm{fee}]}}{V_{t}}$ \\
\hline 0 & 65 & 100.000 & $99.962 \%$ & $0.038 \%$ \\
\hline 5 & 70 & 80.614 & $99.968 \%$ & $0.032 \%$ \\
\hline 10 & 75 & 63.126 & $99.974 \%$ & $0.026 \%$ \\
\hline 15 & 80 & 47.750 & $99.979 \%$ & $0.021 \%$ \\
\hline 20 & 85 & 34.545 & $99.984 \%$ & $0.016 \%$ \\
\hline 25 & 90 & 23.242 & $99.988 \%$ & $0.012 \%$ \\
\hline 30 & 95 & 12.496 & $99.993 \%$ & $0.007 \%$ \\
\hline \multicolumn{5}{|c|}{ Benefits Linked to Act. Value, Case (a) } \\
\hline Time $t$ & Age $x+t$ & $V_{t}$ & $\frac{V_{t}^{[\text {ben }]}}{V_{t}}$ & $\frac{V_{t}^{[\mathrm{fee}]}}{V_{t}}$ \\
\hline 0 & 65 & 100.000 & $99.845 \%$ & $0.155 \%$ \\
\hline 5 & 70 & 80.597 & $99.869 \%$ & $0.131 \%$ \\
\hline 10 & 75 & 63.102 & $99.892 \%$ & $0.108 \%$ \\
\hline 15 & 80 & 47.721 & $99.913 \%$ & $0.087 \%$ \\
\hline 20 & 85 & 34.515 & $99.933 \%$ & $0.067 \%$ \\
\hline 25 & 90 & 23.207 & $99.952 \%$ & $0.048 \%$ \\
\hline 30 & 95 & 12.458 & $99.972 \%$ & $0.028 \%$ \\
\hline
\end{tabular}

In Table 6, we quote the expected value of the Present Value of Future Profits and the Business Value at time 0, per policy issued, for the various arrangements examined so far. We first note that the magnitude of $\mathbb{E}\left[\mathrm{PVFP}_{0}\right]$ is in line with that of the overall loading (see Table 4). Indeed, a large part of the profit is originated by the loading. As is well-known, large loadings impact negatively on the demand; while $\mathrm{PVFP}_{0}$ measures the profit per policy issued, the total profit gained by the provider also depends on the pool size. This should not be disregarded when performing a profit test of the business with the purpose of identifying a cost-effective solution that may prove attractive to the individual.

As to the business value, first we note that it is not 0 . As commented in Section 2.5, condition (18) is a notional reference, which is useful to set the fee consistently in different situations; not necessarily such a condition leads to a situation of a 0 expected value for the business value, as it emerges from Table 6 . In such a table, the business value is quoted as a proportion of the present value of future profits. We see that such a proportion is different, depending both on the arrangement and the scenario. In view of practical implementations, the fee obtained under condition (18) could be taken as the minimum acceptable fee for the provider. An additional loading could be suggested by further assessments; for example, instead of condition (18), reference to the tail of $\mathrm{BV}_{0}$ could be made, by setting an accepted level for the probability of incurring into a negative business value, or setting a target value for the expected business value. In any case, clearly, the loading must prove to be acceptable for individuals. Investigating this aspect is outside the scope of this paper. 
Table 6. Present Value of Future Profits and Business Value (expected values), at time 0.

\begin{tabular}{|c|c|c|c|c|}
\hline \multirow[t]{2}{*}{ Arrangement } & \multicolumn{2}{|c|}{$\begin{array}{l}\text { Moderate } \\
\text { Aggregate } \\
\text { Deviations }\end{array}$} & \multicolumn{2}{|c|}{$\begin{array}{l}\text { Major Aggregate } \\
\text { Deviations }\end{array}$} \\
\hline & $\mathrm{PVFP}_{0}^{[\text {pool] }}$ & $\frac{\mathrm{BV}_{0}^{[\text {pool] }}}{\operatorname{PVFP}_{0}^{[\text {pool] }}}$ & $\mathrm{PVFP}_{0}^{[\mathrm{pool}]}$ & $\frac{\mathrm{BV}_{0}^{[\text {pool }]}}{\operatorname{PVFP}_{0}^{\text {[pool] }}}$ \\
\hline Fixed benefits & 0.820 & $25.160 \%$ & 2.713 & $29.071 \%$ \\
\hline $\begin{array}{l}\text { Benefits linked to surv. prob., } \\
\text { case (a) }\end{array}$ & 0.034 & $52.960 \%$ & 0.341 & $28.146 \%$ \\
\hline $\begin{array}{l}\text { Benefits linked to act. value, } \\
\text { case (a) }\end{array}$ & 0.151 & $42.137 \%$ & 0.387 & $23.347 \%$ \\
\hline $\begin{array}{l}\text { Benefits linked to surv. prob., } \\
\text { case (b) }\end{array}$ & 0.076 & $17.690 \%$ & 1.140 & $24.734 \%$ \\
\hline $\begin{array}{l}\text { Benefits linked to act. value, } \\
\text { case (b) }\end{array}$ & 0.151 & $42.137 \%$ & 0.246 & $9.468 \%$ \\
\hline
\end{tabular}

We finally note that the annual profits, the present value of future profits and the business value can be affected by basis risk in mortality, i.e., by a different mortality in the pool than in the reference population; however, such an aspect is not included in the assessments summarized in this section.

\section{Conclusions}

In this paper, we investigate annuity designs in which the benefit amount is adjusted in time in relation to a given mortality/longevity experience, compared to a chosen benchmark. Such designs imply a new definition of the longevity guarantee, which deserves attention, given that individuals prove to be dissatisfied with traditional annuities, but need to obtain longevity protection in the private market.

In this paper, in particular, we are concerned with a pricing structure which is innovative for an annuity product. Instead of the traditional upfront single loading, we consider periodic fees, which seem more versatile to introduce opportunities of flexibility into the product. We consider a periodic fee charged year by year to the policy fund value, and we show that this identifies a discount factor, to be used for pricing and reserving. Trying to match traditional with market pricing rules, we assess the periodic fee using a condition expressed in terms of business value. This way, the fees incorporate an allowance for both the expected profit and the risk retained by the provider.

Future steps in the research may concern an assessment of individual preferences in respect of the alternative linking solutions. The business value for the provider could be further examined, by addressing the demand function, as well as the limited liability put option. The implications of switching between alternative linking rules or guarantees require a specific study, as well as the possibility of updating the periodic fee after issue. Addressing a pool consisting of multiple cohorts or heterogeneous in other respects is also significant, in particular to detect possible smoothing effects if the linking coefficient accounts for the mortality experienced over different cohorts. An explicit pricing of the guarantees is a topic to further develop. In this regard, modelling guarantees as financial options offers the possibility to test pricing models developed in that field. Matching the mortality/longevity with a financial linking should also be considered, as most annuities in the market are participating in respect of the return on investments.

Funding: This research received no external funding.

Institutional Review Board Statement: Not applicable.

Informed Consent Statement: Not applicable. 
Data Availability Statement: Data is contained within the paper, as they are entirely simulated on the assumptions stated.

Acknowledgments: The author wish to thank the anonymous referees for their constructive comments and suggestions.

Conflicts of Interest: The author declares no conflict of interest.

\section{References}

Andersen, Carsten, and Peter Skjodt. 2007. Pension institutions and annuities in Denmark. Policy Research Working Paper, The World Bank. Washington, DC: World Bank.

Bacinello, Anna Rita, Pietro Millossovich, and An Chen. 2018. The impact of longevity and investment risk on a portfolio of life insurance liabilities. European Actuarial Journal 8: 257-90. [CrossRef]

Bacinello, Anna Rita, Pietro Millossovich, Annamaria Olivieri, and Ermanno Pitacco. 2011. Variable annuities: A unifying valuation approach. Insurance: Mathematics and Economics 49: 285-97. [CrossRef]

Bernhardt, Thomas, and Catherine Donnelly. 2019. Modern tontine with bequest: Innovation in pooled annuity products. Insurance: Mathematics and Economics 86: 168-88. [CrossRef]

Blackburn, Craig, Katja Hanewald, Annamaria Olivieri, and Michael Sherris. 2017. Longevity risk management and shareholder value for a life annuity business. ASTIN Bulletin 47: 43-77. [CrossRef]

Bravo, Jorge Miguel, and Najat El Mekkaoui de Freitas. 2018. Valuation of longevity-linked life annuities. Insurance: Mathematics and Economics 78: 212-29. [CrossRef]

Cairns, Andrew J. G., David P. Blake, Amy Kessler, and Marsha Kessler. 2020. The Impact of COVID-19 on Future Higher-Age Mortality. May 19. Available online: https:// ssrn.com/abstract=3606988 (accessed on 3 August 2021). [CrossRef].

Chen, An, and Manuel Rach. 2019. Options on tontines: An innovative way of combining tontines and annuities. Insurance: Mathematics and Economics 89: 182-92.

Chen, An, Manuel Rach, and Thorsten Sehner. 2020. On the optimal combination of annuities and tontines. Astin Bulletin 50: 95-129. [CrossRef]

Chen, An, Montserrat Guillen, and Manuel Rach. 2021. Fees in tontines. Insurance: Mathematics and Economics 100: 89-106.

Chen, An, Peter Hieber, and Jakob K. Klein. 2019. Tonuity: A novel individual-oriented retirement plan. ASTIN Bulletin 49: 5-30. [CrossRef]

Davidoff, Thomas, Jeffrey R. Brown, and Peter A. Diamond. 2005. Annuities and Individual Welfare. American Economic Review 95: 1573-90. [CrossRef]

Denuit, Michel, Steven Haberman, and Arthur Renshaw. 2011. Longevity-indexed life annuities. North American Actuarial Journal 15: 97-111. [CrossRef]

Donnelly, Catherine. 2015. Actuarial fairness and solidarity in pooled annuity funds. ASTIN Bulletin 45: 49-74. [CrossRef]

Donnelly, Catherine, Montserrat Guillén, and Jens Perch Nielsen. 2013. Exchanging uncertain mortality for a cost. Insurance: Mathematics and Economics 52: 65-76. [CrossRef]

Duffie, Darrell. 2001. Dynamic Asset Pricing Theory, 3rd ed. Princeton: Princeton University Press.

Hanbali, Hamza, Michel Denuit, Jan Dhaene, and Julien Truffin. 2019. A dynamic equivalence principle for systematic longevity risk management. Insurance: Mathematics and Economics 86: 158-67. [CrossRef]

Lee, Ronald, and Lawrence Carter. 1992. Modelling and forecasting US mortality. Journal of the American Statistical Association 87: 659-75.

McKever, Kent. 2009. A short history of tontines. Fordham Journal of Corporate and Financial Law 15: 491-521.

Milevsky, Moshe A. 2014. Portfolio choice and longevity risk in the late Seventeenth century: A re-examination of the first English tontine. Financial History Review 21: 225-58. [CrossRef]

Milevsky, Moshe A. 2020. Is COVID-19 a Parallel Shock to the Term Structure of Mortality? Available online: https:/ / moshemilevsky. com/wp-content/uploads/2020/05/MILEVSKY_20MAY2020_AMAZON.pdf (accessed on 3 August 2021).

Milevsky, Moshe A., and Thomas S. Salisbury. 2015. Optimal retirement income tontines. Insurance: Mathematics and Economics 64: 91-105. [CrossRef]

Olivieri, Annamaria, and Ermanno Pitacco. 2009. Stochastic mortality: The impact on target capital. ASTIN Bulletin 39: 541-63. [CrossRef]

Olivieri, Annamaria, and Ermanno Pitacco. 2020a. Linking annuity benefits to the longevity experience: Alternative solutions. Annals of Actuarial Science 14: 316-37. [CrossRef]

Olivieri, Annamaria, and Ermanno Pitacco. 2020b. Longevity-Linked Annuities: How to Preserve Value Creation against Longevity Risk. In Life Insurance in Europe. Edited by M. Borda, S. Grima and I. Kwiecień. Financial and Monetary Policy Studies. Berlin: Springer, vol. 50, pp. 103-26.

Peijnenburg, Kim, Theo Nijman, and Bas J. M. Werker. 2016. The Annuity Puzzle Remains a Puzzle. Journal of Economic Dynamics and Control 70: 18-35. [CrossRef]

Piggott, John, Emiliano A. Valdez, and Bettina Detzel. 2005. The simple analytics of a pooled annuity fund. The Journal of Risk and Insurance 72: 497-520. [CrossRef] 
Pitacco, Ermanno. 2016. Guarantee structures in life annuities: A comparative analysis. The Geneva Papers on Risk and Insurance-Issues and Practice 41: 78-97. [CrossRef]

Qiao, Chao, and Michael Sherris. 2013. Managing systematic mortality risk with group self-pooling and annuitization schemes. The Journal of Risk and Insurance 80: 949-74.

Richter, Andreas, and Frederik Weber. 2011. Mortality-Indexed annuities. Managing longevity risk via product design. North American Actuarial Journal 15: 212-36. [CrossRef]

Stamos, Michael Z. 2008. Optimal consumption and portfolio choice for pooled annuity funds. Insurance: Mathematics and Economics 43: 56-68. [CrossRef]

Weinert, Jan Hendrik, and Helmut Gründl. 2021. The modern tontine. European Actuarial Journal 11: 49-86. [CrossRef]

Yaari, Menahem E. 1965. Uncertain lifetime, life insurance, and the theory of the consumer. The Review of Economic Studies 32: 137-50. [CrossRef] 